There is as yet no agreed measure of obesity in children. ${ }^{1}$ The prevalence of obesity increases with age, and the centiles defining adult obesity are unlikely to yield a similar proportion of clinically obese children. Furthermore, targeting obese children is unlikely to identify those most at risk of becoming obese adults. ${ }^{4}$ Visceral fat distribution is likely to prove a better predictor of subsequent morbidity than absolute fat mass. ${ }^{5}$ The charts allow change in body mass index to be observed in an individual child, but this may be no more valuable than the longitudinal monitoring of height and weight from which body mass index is derived. Children with diverging height and weight centiles should perhaps be referred rather than waiting for body mass index to cross an arbitrary cut off point, especially one that has no proved clinical correlate.
Contributors: JM devised the investigation, analysed the data, and contributed to the writing of the paper. LV was the coordinator and principal investigator of the Wessex Growth Study and contributed to the writing of the paper.

Funding: The Wessex Growth Study is funded by a grant to the Wessex Medical Trust from Pharmacia Upjohn and by a grant from the NHS S and W research and development fund.

Competing interests: None declared.

1 Prentice AM. Body mass index standards for children. BMJ 1998; 317:1401-3.

2 Freeman JV, Power C, Rodgers B. Weight-for-height indices of adiposity: relationships with height in childhood and early adult life. Int J Epidemiol 1995;34:970-6.

3 Hulse JA. Referral criteria for growth screening. J Med Screening 1995;2:168-70.

4 Power C, Lake JK, Cole TJ. Body mass index and height from childhood to adulthood in the 1958 British birth cohort. Am J Clin Nutr 1997;66:1094-101.

5 Ruderman N, Chisholm D, Pi-Sunyer X, Schneider S. The metabolically obese, normal-weight revisited. Diabetes 1998;47(5):699-713.

(Accepted 20 May 1999)

\title{
Maternal mortality in the former East Germany before and after reunification: changes in risk by marital status
}

Oliver Razum, Albrecht Jahn, Rachel Snow

Department of Tropical Hygiene and Public Health, Im Neuenheimer Feld 324, 69120,

Heidelberg,

Germany

Oliver Razum

epidemiologist

Albrecht Jahn obstetrician

Rachel Snow reproductive biologist

Correspondence to: Dr Razum

oliver.razum@urz. uni-heidelberg.de

BMJ 1999;319:1104-5
Maternal mortality is a sensitive indicator of social inequalities and is closely linked to socioeconomic and marital status. In the former West Germany the risk of maternal death is 1.8 times higher in unmarried women than in married women, ${ }^{1}$ and being unmarried is closely associated with lower socioeconomic status. ${ }^{2}$

German reunification, which took place in 1990, was accompanied by major social and societal changes in the former East Germany. Overall fertility declined by $60 \%$ between 1989 and 1994, but the proportion of births to unmarried women rose progressively from $23 \%$ in 1980 to $42 \%$ in 1996 . We examined the impact of marital status on maternal mortality in the period before and the period after German reunification in the area covered by the former East Germany (referred to in this article as eastern Germany).

\section{Methods and results}

We calculated the maternal mortality ratio by relating the number of maternal deaths (codes 630-676 according to the international classification of diseases, ninth revision) among women resident in eastern Germany in 1980-96 to the respective number of live births, using national register data. We investigated the effect of marital status, controlling for maternal age and year of death, in a Poisson regression model.

Altogether, 413 maternal deaths and 2.99 million live births were reported (table). The overall maternal mortality ratio was stable before, and declined after, reunification. Before reunification, unmarried women had a risk of maternal death equal to that of married women (table); after reunification, they had 2.6 times the age adjusted risk of married women. Unmarried status thus became a significant risk factor for maternal mortality in eastern Germany after reunification.

\section{Comment}

Maternal death registration in the former East Germany required panel review and compulsory postmortem examination and was regarded as nearly complete. $^{3}$ At reunification, the more relaxed reporting system of the former West Germany was adopted. As no evidence exists of major differences in accessibility or quality of obstetric care in the former East Germany

Demographic data and relative risk of maternal death by marital status, eastern Germany

\begin{tabular}{|c|c|c|}
\hline Variable & Before reunification, 1980-90 & After reunification, 1991-6 \\
\hline \multicolumn{3}{|l|}{ Demography: } \\
\hline Total No of live births (No and proportion of unmarried women) & 2453627 (767 619; 31.3\%) & $532394(222$ 126; 41.7\%) \\
\hline Total No of maternal deaths (№ and proportion of cases of unmarried women) & $368(102 ; 27.7 \%)$ & $45(26 ; 57.8 \%)$ \\
\hline Overall crude maternal mortality ratio per 100000 live births $(95 \% \mathrm{Cl})$ & 15 (13.5 to 16.6$)$ & $8.5(6.3$ to 11.3$)$ \\
\hline \multicolumn{3}{|l|}{ Modelling: } \\
\hline Crude relative risk of unmarried $v$ married women $(95 \% \mathrm{Cl})$ & $0.84(0.67$ to 1.06$)$ & $1.91(1.06$ to 3.45$) \dagger$ \\
\hline Age adjusted relative risk of unmarried $v$ married women $(95 \% \mathrm{Cl})$ & $1.08(0.85$ to 1.36$)$ & 2.56 (1.41 to 4.63$) \ddagger$ \\
\hline
\end{tabular}


compared with eastern Germany after reunification, the decrease in overall maternal mortality after reunification probably reflects more incomplete reporting. The observed emergence of a higher relative risk among unmarried women is less likely to be an artefact: the definition of marital status in data for eastern Germany has remained unchanged over the study period, and a change in the completeness of reporting of maternal deaths is unlikely to be associated with marital status.

Two phenomena, however, show a distinct temporal association with, and could thus help to explain, the emergence of unmarried status as a marker of increased maternal risk in eastern Germany: changes in support programmes for pregnant women and mothers, and socioeconomic changes. Support measures in the former East Germany included cash incentives to women who regularly attended prenatal care; a follow up of women who did not attend ${ }^{4}$; and a guaranteed job for women with children. Single mothers were guaranteed social protection and support by the constitution. ${ }^{5}$ After reunification these measures were eliminated. In eastern Germany in particular, job security is now very low and the number of crèches is declining sharply. Concurrently, being unmarried became associated with lower socioeconomic status, as was already the case in the former West Germany. ${ }^{25}$ For example, in unified Germany, 22\% of unmarried mothers but only $2 \%$ of married mothers with children aged under 18 years received social welfare payments in $1996 .{ }^{1}$
After reunification, unmarried mothers in the study area emerged as a group with higher maternal risk and lower socioeconomic status, similar to unmarried women in the former West Germany. ${ }^{1}$ As an increasing proportion of all births occur outside marriage both in Germany and in many other countries, further research is needed to establish to what degree the special support services in the former East Germany contributed towards a measure of health equity among pregnant women, regardless of marital status.

We thank Ms Köhn of the Statistical Office in Berlin and Mr Hammer of the Federal Statistical Office in Wiesbaden for providing the data on live births and mortality. Matthias Borchert gave helpful comments on an earlier version of this paper.

Contributors: The authors jointly conceptualised the study, reviewed background literature, interpreted the findings and drafted the article. OR collated the dataset, performed the statistical analysis, and is the guarantor.

Funding: None.

Competing interests: None declared.

1 Razum O, Jahn A, Blettner M, Reitmaier P. Trends in maternal mortality ratio among women of German and non-German nationality in West Germany, 1980 to 1996. Int J Epidemiol (in press).

2 Habich R, Krause P. Armut. In: Statistisches Bundesamt, ed. Datenreport 1997. Bonn: Bundeszentrale für politische Bildung, 1997:515-25. (Schriftenreihe, No 340.)

3 Welsch H. Mütterliche Mortalität. Arch Gynecol Obstet 1989;245:321-8.

4 Greenberg RA. Maternal and child health services policy in the German Democratic Republic. J Public Health Policy 1984;5:118-30.

5 Drauschke P, Stolzenburg M. Alleinerziehende Frauen nach der Wende im Ostteil Berlins. Was sie gewinnen und was sie verlieren. Bulletin des Zentrums für interdisziplinäre Frauenforschung 1993;6:50-8.

(Accepted 17June 1999)

\section{A lesson to be learnt A word out of place}

Some two years ago we looked after a man in his late 40 s who had had unremitting pleural pain for several weeks. His chest radiograph revealed marked pleural thickening in the distribution of his pain and he had a history of exposure to asbestos dust. We suspected mesothelioma and told him and his family that this was a possible diagnosis and requested permission to carry out a biopsy.

Neither our patient nor his relatives had heard of mesothelioma, but while he was in hospital and unwell his wife busied herself finding out about the disease. She quickly concluded that the diagnosis of mesothelioma was, unfortunately, likely and that this being the case, she preferred her husband to be spared the knowledge of the worst aspects of the condition. She was also worried that the biopsy would have complications, especially seeding of the tumour along the needle track, should the diagnosis have turned out to have been as we feared.

The task fell to me to discuss the various choices regarding further investigation and treatment with the patient, his wife, and their adult children. I had had chance to build up some rapport with all of them as he had by then been in the hospital some time. The first few minutes the conversation went well. I then turned to the options for follow up in the community should we opt not to perform a biopsy. At this point I mentioned Macmillan nurses and I quickly saw the patient's wife become uneasy and leave the room. I rapidly made some excuse to slip out as I knew she would be waiting for me outside.

I had not realised that our patient might equate mention of the Macmillan team with a diagnosis of cancer. While he had not seemed to bat an eyelid when I alluded to Macmillan nurses, his wife was upset at what had happened and blamed me for hinting at a malignant disease. Over the course of a long chat with her and her daughter in the corridor, during which my bleep rang continuously, we determined to discontinue the conversation and not to mention the misunderstanding further.

It was decided not to proceed with the biopsy and, sadly, a few weeks later our patient died. It was subsequently shown that he had had mesothelioma. I remain friendly with our patient's widow who now works tirelessly with the Mesothelioma Society and has raised thousands of pounds for research.

I learnt several valuable lessons from this experience. A family's wishes should be respected where possible, however difficult that may be. While you have a responsibility to relatives, your primary concern must always be to the patient. In this situation I was happy to avoid overt discussion of cancer because we had only a suspicion of its presence. If, however, the patient had directly asked whether malignant disease had been a possibility I would have been unable to lie to him, whatever the relatives' feelings. Words must be chosen with the utmost care during interactions with patients and relatives especially at times of great emotion. Getting on well with patients and those around them engenders understanding and harmony as well as mutual trust. No matter how bad a disagreement, it is important to work with relatives for what is in the best interest of the patient.

Solomon Almond, senior registrar, Liverpool

We welcome articles up to 600 words on topics such as A memorable patient, A paper that changed my practice, My most unfortunate mistake, or any other piece conveying instruction, pathos, or humour. If possible the article should be supplied on a disk. Permission is needed from the patient or a relative if an identifiable patient is referred to. We also welcome contributions for "Endpieces," consisting of quotations of up to 80 words (but most are considerably shorter) from any source, ancient or modern, which have appealed to the reader. 